\title{
Lysozyme in the tears of newborn babies
}

\author{
P. C. ETCHES, F. LEAHY, D. HARRIS, AND J. D. BAUM
}

John Radcliffe Hospital, Oxford

SUMMARY Tear lysozyme concentration was measured in term, preterm, and small-for-dates ${ }_{-}^{\circ}$ infants using a modification of the lysoplate technique. The lysozyme concentration was greater in $\vec{\omega}$ the term infant than in preterm and small-for-dates infants. The values were found to increase $\frac{\rho}{\mathrm{O}}$ with birthweight and gestation to a term value which is similar to that described in adults. There $\frac{O}{\circ}$ was no relationship between the lysozyme concentration and the rate of tear production.

In 1922 Fleming discovered 'a remarkable bacteriolytic element' in nasal mucus which was capable of lysing certain bacteria, particularly Micrococcus lysodeikticus, which he called lysozyme. The lysozyme is identical in all human secretions and tissues but lysozyme in hen egg white is different (Jollés and Jollés, 1967). Lysozyme acts by breaking down cell wall mucopolysaccharides; this action has been precisely defined and this group of enzymes can be classified as muramidases or $\mathrm{N}$-acetylmuramide glycanohydrolases (Chipman and Sharon, 1969). One source of human lysozyme is in the urine of patients with monocytic and myeloid leukaemia (Osserman and Lawlor, 1966). However, lysozyme is an enzyme that is found in many secretions, including human milk and human tears (Jollés and Jollés, 1967).

Sticky eyes are common in newborn infants. As a possible predisposing factor to eye infections, we wondered whether there was any deficiency in the lysozyme activity in neonatal tears. The concentration of lysozyme in adult human tears has been measured (Friedland, et al., 1972; Pietsch and Pearlman, 1973; Mackie and Seal, 1976), but there has been no systematic study of the amount present in the tears of newborn babies.

\section{Patients}

Three groups of infants were studied: 20 term infants of appropriate weight for gestation, 17 preterm infants appropriate in weight for gestation, and

Women's Center, Winnipeg, Manitoba, Canada

F. LEAHY, clinical fellow

Department of Paediatrics, John Radcliffe Hospital, Oxford

P. C. ETCHES, senior paediatric registrar

D. HARRIS, senior medical laboratory scientific officer

J. D. BAUM, clinical reader in paediatrics
Table Characteristics of the three groups of babies

\begin{tabular}{|c|c|c|c|}
\hline & $\begin{array}{l}\text { Term } \\
(n=20)\end{array}$ & $\begin{array}{l}\text { Preterm } \\
(n=17)\end{array}$ & $\begin{array}{l}\text { Term (small- } \\
\text { for-dates) } \\
(n=10)\end{array}$ \\
\hline \multicolumn{4}{|c|}{ Birthweight (kg) } \\
\hline $\begin{array}{l}\text { Mean } \\
\text { Range }\end{array}$ & $\begin{array}{l}3 \cdot 40 \\
2 \cdot 72-4 \cdot 04\end{array}$ & $\begin{array}{l}2 \cdot 19 \\
1 \cdot 05-3 \cdot 12\end{array}$ & $\begin{array}{l}2 \cdot 49 \\
2 \cdot 02-2 \cdot 81\end{array}$ \\
\hline \multicolumn{4}{|c|}{ Gestation (weeks) } \\
\hline $\begin{array}{l}\text { Mean } \\
\text { Range }\end{array}$ & $\begin{array}{l}39 \cdot 8 \\
37-41\end{array}$ & $\begin{array}{l}33 \cdot 7 \\
28-36 \cdot 5\end{array}$ & $\begin{array}{l}38 \cdot 9 \\
37-41\end{array}$ \\
\hline
\end{tabular}

10 term infants who were small-for-dates (Table). Gestational age was based on the date of the mother's $\frac{2}{\varnothing}$

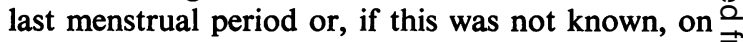
the baby's physical and neurological characteristics (Dubowitz et al., 1970). We took samples from normal uninfected eyes within the first 24 hours after birth. In most cases the baby lay quietly sleeping while samples were collected. Permission for the study was granted by the Oxford Area Health Authority (Teaching) Ethics Committee, and in each case parental permission for collecting the samples was obtained.

\section{Method of measuring tear lysozyme concentration}

The tears were collected by the method described by Schirmer (1903). A commercially available stan- N dardised sterile strip of filter paper (Schirmer tear $N$ test: SMP International Inc.) was bent at a right- $N$ angle at the notch, $5 \mathrm{~mm}$ from one end. This was gently hooked over the lower lid so that the short rounded $5 \mathrm{~mm}$ portion was resting in the lower conjunctival sac at the medial side of the eye. After $\mathbb{D}$ exactly 5 minutes the strip was removed and the length beyond the notch which had been wetted by tears was measured. Occasionally, if the rate of tear production was high, the strip was removed when the whole of its length (30 mm from the notch) 
became wet, and the time noted. In this way we obtained a crude index of the rate of tear production, as well as obtaining a sample of tears.

'Lysoplates' were prepared according to a modification of the method of Bonavida and Sapse (1968). $1 \%$ mass/vol. agarose was dissolved in $0.066 \mathrm{~mol} / 1$ sodium phosphate buffer, $\mathrm{pH} 6 \cdot 24$, containing $1 \%$ sodium chloride, by heating in a boiling water bath until the agarose dissolved. This solution was cooled to $65^{\circ} \mathrm{C}$ and a thick suspension of $M$. lysodeikticus added to make the concentration of cells $0.05 \% .10 \mathrm{ml}$ of this mixture was placed in each plate, solidified at room temperature, and stored at $4^{\circ} \mathrm{C}$.

The lysoplate technique depends on the measurement of the diameter of the zone of lysis in the $M$. lysodeikticus suspension produced by the lysozyme which is placed on the surface of the agarose and incubated at $37^{\circ} \mathrm{C}$. Others have taken a $5 \mathrm{~mm}$ length of the Schirmer strip, but we found by weighing that this produced a piece of paper which varied greatly in size and therefore would carry a variable quantity of the solution. We therefore constructed a circular punch to produce discs of filter paper $4 \mathrm{~mm}$ in diameter so as to standardise the loading volume. To establish that this did, in fact, standardise the loading volume, a $4 \mathrm{~mm}$ disc was punched $5-10 \mathrm{~mm}$ from the notched end of a strip which had been wetted by dipping the notched end in water. The water-loaded disc was weighed on a balance accurate to one microgram. The disc was reweighed after it had dried and hence the amount of water taken up was obtained. In a series of 25 pilot experiments the mean weight of the disc was $0.975 \mathrm{mg}$ (SD \pm 0.086 ). These discs took up water with a mean weight of $1.298 \mathrm{mg}$ (SD $\pm 0 \cdot 233$ ). We then found that a standard solution dried in air at room temperature resulted in no loss of lysozyme activity.

Other workers (Bonavida and Sapse, 1968; Peeters and Vantrappen, 1977) have drawn attention to the problems of the lysoplate method. The time of incubation (24 hours) and the temperature $\left(37^{\circ} \mathrm{C}\right)$ are important as are the $\mathrm{pH}$ and ionic strength. It is important to use agarose and not agar because lysozyme binds to the latter but not to the former (Bonavida et al., 1967). The thickness of the agarose in the plate is important as is the micrococcus concentration: it is preferable to use the same 'batch' of plates throughout. We showed that there was no variation in the zone of lysis produced by a lysozyme standard disc when plates were stored for a period of 4 weeks at $4^{\circ} \mathrm{C}$.

A calibration curve was constructed from known standards of human lysozyme. All samples were measured using a single 'batch' of plates and an internal standard was included in each case.

\section{Results}

The rate of wetting of the strip in $\mathrm{mm} / \mathrm{min}$ was used as an index of the rate of tear production and plotted against the zone of lysis; there was no correlation demonstrable. This indicates that an alteration in the rate of tear production does not affect lysozyme concentration.

Fig. 1 shows the distribution of the zones of lysis (corresponding to the lysozyme concentration) produced from each eye from each patient in the three groups (one sample was lost from one preterm infant). The zone of lysis is significantly greater in the term babies compared both with the preterm babies and the small-for-dates babies.

The zone of lysis against gestation is shown for appropriate weight for gestation babies in Fig. 2 . The lysozyme concentration increased with increasing gestational age. The mean zone of lysis for term babies, $27.3 \mathrm{~mm}$, corresponds to a lysozyme concentration of $1118 \mu \mathrm{g} / \mathrm{ml}$. Fig. 3 shows the zones of

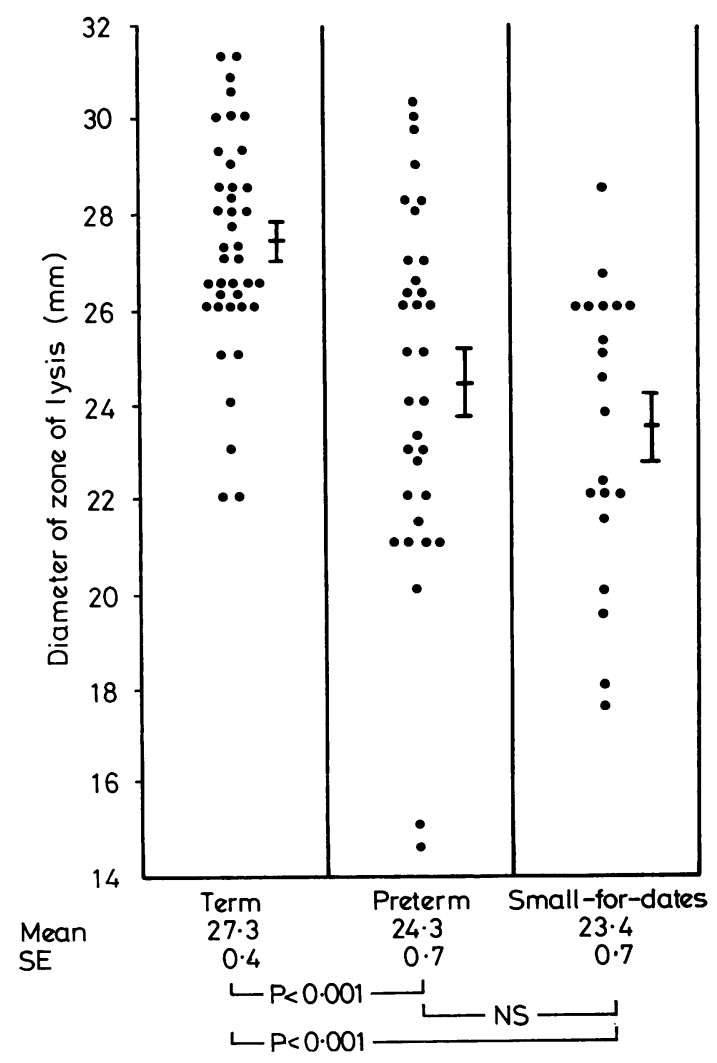

Fig. 1 Diameters of the zone of lysis produced in the three groups of babies. Means $\pm 1 S E$. 


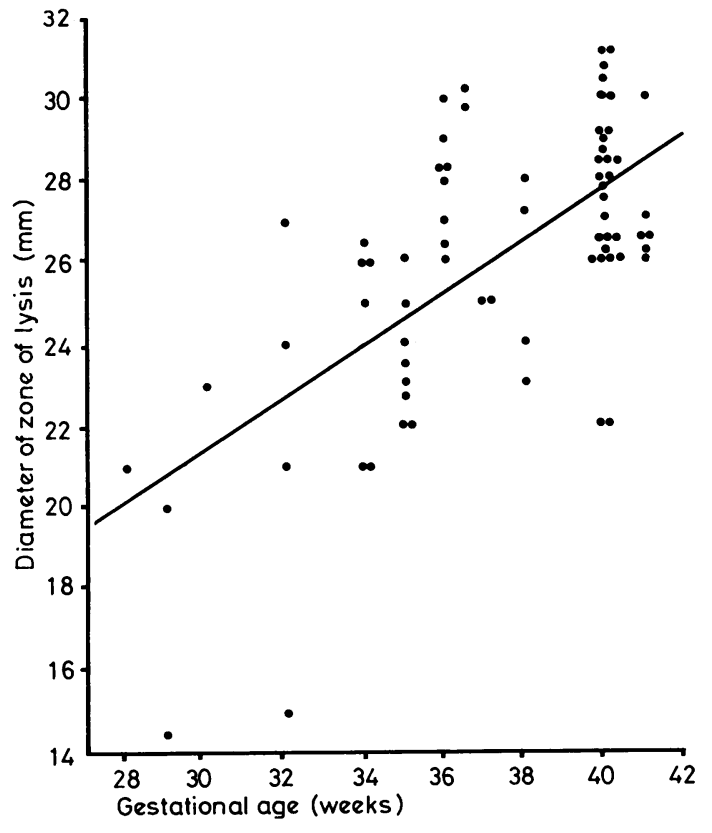

Fig. 2 Diameter of the zone of lysis plotted against gestation in appropriate weight for gestation babies. $r=0.65, P<0.001$.

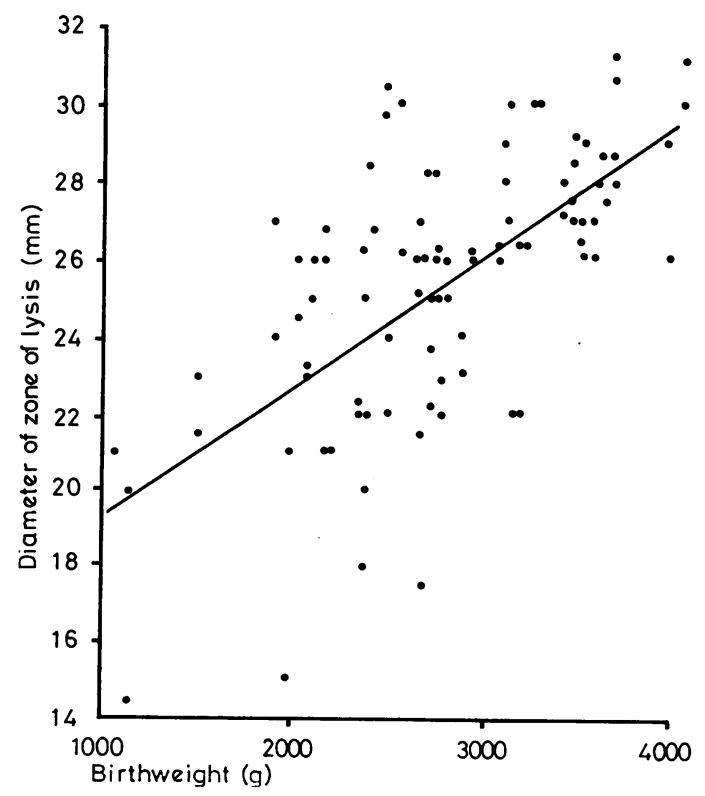

Fig. 3 Diameter of the zone of lysis plotted against birthweight for all babies. $r=0.65, P<0.001$. lysis plotted against birthweight for all babies, including the infants born at term small-for-dates. The lysozyme concentration increases with increasing birthweight.

\section{Discussion}

There are at least 7 tear proteins (Josephson and Weiner, 1968; Sapse et al., 1969) of which the main components are pre-albumin, lysozyme, lactoferrin, and immunoglobulin A (Broekhuyse, 1974). Ridley (1928) described the bactericidal action of tear 'lysozyme' on a wide variety of micro-organisms and it later became clear that although lysozyme may be effective and protective against some pathogenic bacteria, the concentration has only to be decreased slightly for it to become ineffective (Ridley, cited by Regan, 1950). Thompson and Gallardo (1941) found that the antistaphylococcal action of tears was destroyed by acidification and heating, although the lysozyme content remained unaltered. Subsequently Friedland et al. (1972) demonstrated a potent 'nonlysozyme antibacterial factor' in tears.

The normal values for human tear lysozyme in adults was found by Bonavida and Sapse (1968) to be about $1700 \mu \mathrm{g} / \mathrm{ml}$, although the values in their 4 infants were less $(700-800 \mu \mathrm{g} / \mathrm{ml})$. The mean result for our term infants was $1118 \mu \mathrm{g} / \mathrm{ml}$ which lies between these two values. However, the concentration of tear lysozyme varies with both gestation and birthweight.

In 1928 Ridley found a decreased lysozyme activity in certain eye diseases, including epiphora, and other workers have subsequently confirmed this (Sapse et al., 1968; El-Gammal and Mostafa, 1971). One suggestion has been that an increased flow of tears produces a dilution effect. In normal eyes, however, Mackie and Seal (1976) showed very little difference in lysozyme concentration between slow and fast tear producers, and our results with neonates are similar.

It seems that newborn infants without eye infections have no marked deficiency of tear lysozyme. Preterm infants are not generally thought to be especially prone to eye infections, yet the lysozyme concentration in tears is lower with shorter gestation.

However it is likely that tear lysozyme represents only one of a wide range of synergistic antimicrobial factors. We have no additional information on these other factors in the newborn eye, nor on how the levels of lysozyme and nonlysozymal factors behave in infants with conjunctivitis.

We thank Dr Colin Black of the Department of Zoology, Oxford, for advice and supplying the human lysozyme; $\mathrm{Mr}$ Anthony Bron, reader in 
ophthalmology, Oxford, for his advice; Mrs Alison Smith for statistical help; and Mr P. Goddard for making the circular punch for producing discs from the Schirmer strips.

\section{References}

Bonavida, B., Sapse, A. T., and Sercarz, E. E. (1967). Human tear lysozyme. I. Purification, physicochemical, and immunochemical characterisation. Journal of Laboratory and Clinical Medicine, 70, 951-962.

Bonavida, B., and Sapse, A. T. (1968). Human tear lysozyme. II. Quantitative determination with standard Schirmer strips. American Journal of Ophthalmology, 66, 70-76.

Broekhuyse, R. M. 1974). Tear lactoferrin: a bacteriostatic and complexing protein. Investigative Ophthalmology, 13, $550-554$.

Chipman, D. M., and Sharon, N. (1969). Mechanism of lysozyme action. Science, 165, 454-465.

Dubowitz, L. M. S., Dubowitz, V., and Goldberg, C. (1970). Clinical assessment of gestational age in the newborn infant. Journal of Pediatrics, 77, 1-10.

El-Gammal, M. Y., and Mostafa, M. S. (1971). Estimation of tear lysozyme in some eye diseases. Bulletin of the Ophthalmological Society of Egypt, 64, 285-297.

Fleming, A. (1922). On a remarkable bacteriolytic element found in tissues and secretions. Proceedings of the Royal Society of London, (Series B), 93, 306-317.

Friedland, B. R., Anderson, D. R., and Forster, R. K. (1972). Non-lysozyme antibacterial factor in human tears. American Journal of Ophthalmology, 74, 52-59.

Jollés, J., and Jollés, P. (1967). Human tear and human milk lysozymes. Biochemistry, 6, 411-417.

Josephson, A. S., and Weiner, R. S. (1968). Studies of the proteins of lact imal secretions. Journal of Immunology, 100, 1080-1092.
Mackie, I. A., and Seal, D. V. (1976). Quantitative tear lysozyme assay in units of activity per microlitre. British Journal of Ophthalmology, 60, 70-74.

Osserman, E. F., and Lawlor, D. P. (1966). Serum and urinary lysozyme (muramidase) in monocytic and monomyelocytic leukemia. Journal of Experimental Medicine, 124, 921-951.

Peeters, T. L., and Vantrappen, G. R. (1977). Factors influencing lysozyme determinations by the lysoplate method. Clinica chimica acta, 74, 217-225.

Pietsch, R. L., and Pearlman, M. E. (1973). Human tear lysozyme variables. Archives of Ophthalmology, 90, 94-96.

Regan, E. (1950). The lysozyme content of tears. American Journal of Opthalmology, 33, 600-605.

Ridley, F. (1928). An antibacterial body present in great concentration in tears and its relation to infection of the human eye. British Journal of Ophthalmology, 12, 532-538.

Sapse, A. T., Bonavida, B., Stone, W., Jr, and Sercarz, E. E. (1968). Human tear lysozyme. III. Preliminary study on lysozyme levels in subjects with smog eye irritation. American Journal of Ophthalmology, 66, 76-80.

Sapse, A. T., Bonavida, B., Stone, W., Jr, and Sercarz, E. E. (1969). Proteins in human tears. I. Immunoelectrophoretic patterns. Archives of Ophthalmology, 81, 815-819.

Schirmer, O. (1903). Studien zur Physiologie und Pathologie der Tränenabsonderung und Tränenabfuhr. Archiv für Ophthalmologie, 56, 197-291.

Thompson, R., and Gallardo, E. (1941). The antibacterial action of tears on staphylococci. American Journal of Ophthalmology, 24, 635-640.

Correspondence to Dr P. C. Etches, John Radcliffe Hospital, Department of Paediatrics, Headington, Oxford OX3 9DU.

Received 11 July 1978 